\title{
USO DO VPA: UMA FERRAMENTA MELHOR PARA A AVALIAÇÃO DE OPERAÇOEES
}

\section{RESUMO}

Uma das práticas mais difundidas para a avaliação de ativos operacionais é o fluxo de caixa descontado, ou FCD. Contudo, uma das versões mais comumente aceitas de FCD, o custo médio ponderado de capital, ou WACC no original inglês, tornou-se obsoleta. Este artigo discute uma metodologia alternativa ao WACC, chamada de VPA (valor presente ajustado), ou APV (adjusted present value), em inglês. 0 artigo mostra que essa metodologia apresenta vantagens superiores quando comparada ao WACC, especificamente pelo fato de oferecer mais informações de relevância administrativa, a um índice menor de erro, ajudando os executivos a analisar não só quanto vale um ativo, mas também a origem de seu valor.

\section{Timothy A. Luehrman}

Harvard Business School

\footnotetext{
ABSTRACTO ne of the most disseminated ways of valuing operating assets is discounted Cash flow, or DCF. But weighted average cost of capital, or WACC - one of the most commonly accepted forms of DCF - has become obsolete. This article discusses an alternative to WACC known as adjusted present value, or APV. The article shows that this new methodology is greatly superior to WACC, due specially to the fact that it provides additional managerially relevant information at lower error levels, helping executives determine not only how much an asset is worth, but also where its value comes from.
}

PALAVRAS-CHAVE Opções reais, avaliação de ativos, fluxo de caixa descontado, custo médio ponderado de capital, valor presente ajustado.

KEYMORDSReal options, asset valuing, discounted cash-flow, weighted-average cost of capital, adjusted present value. 


\section{INTRODUÇÃO}

Se você aprendeu as técnicas de aval iação há al guns anos, é provável que esteja na hora de passar por uma reciclagem. Você certamente aprendeu que a boa prática de avaliação de ativos operacionais - de um negócio, uma fábrica, uma linha de produto ou uma posição de mercado existentes - era usar um método de fluxo de caixa descontado ( $F C D)$. Isso ainda é verdade. $M$ as a versão do FCD que tem sido aceita como padrão nos últimos 20 anos tornou-se obsoleta - a saber, usar o custo médio ponderado do capital, em inglês weighted average cost of capital, ou WACC.

É verdade que as escolas de Administração e os manuais continuam a ensinar a abordagem pelo WACC. Isso ocorre porque ele está à disposição e é considerado um padrão, e não porque tenha mel hor desempenho. Hoje, as mesmas escolas e os mesmos livros também apresentam metodologias al ternativas. Uma delas, chamada de Valor Presente Ajustado (VPA - em inglês adjusted present value), é especialmente versátil e confiável, e substituirá o WACC como metodologia preferida dos generalistas.

Para gestores que têm negócios a administrar, a questão de qual método de avaliação usar sempre se reduziu a uma comparação pragmática entre as alternativas. 0 que poderíamos usar em vez do WACC? Assim como este último, o VPA foi criado para avaliar operações ou ativos existentes, ou seja, qualquer ativo hoje existente que venha a gerar fluxos de caixa no futuro. Este é o tipo mais básico e comum de problema de avaliação com que

Figura 1 - VPA: Os fundamentos da idéia.

\section{Valor do caso básico}

valor do projeto como

se fosse totalmente

financiado com

capital próprio

0 VPA segrega e analisa separadamente os componentes de valor. O WACC, por outro lado, agrupa na taxa de desconto todos os efeitos colaterais do financiamento. deparam os administradores. Por que optar pelo VPA e não pelo WACC?

Para começar, o VPA sempre funciona nos casos em que o WACC também funciona e, em alguns casos, quando este não funciona. Em segundo lugar, o VPA é menos sujeito a erros graves do que o WACC. Mas, e isso é o mais importante, os executivos verão que o poder do VPA está nas maiores informações de relevância administrativa que ele é capaz de oferecer: o VPA pode ajudar a analisar não só quanto vale um ativo, mas também de onde vem o valor.

Todas as metodologias de fluxo de caixa descontado envolvem a previsão de fluxos de caixa futuros e, então, seu desconto ao valor presente a uma taxa que reflita seu risco. Mas as metodologias diferem quanto a detalhes práticos, principal mente em relação a como consideram o valor criado ou destruído por manobras financeiras e não necessariamente pelas operações. A abordagem pelo VPA analisa as manobras financeiras em separado e então acrescenta seu valor ao do negócio (ver Figura 1). A abordagem pelo WACC ajusta a taxa de desconto (o custo do capital) de maneira a refletir melhorias financeiras. Os anal istas aplicam a taxa de desconto ajustada diretamente aos fluxos de caixa do negócio. Admite-se que o WACC seja capaz de lidar, automaticamente, com os efeitos colaterais financeiros, sem necessidade de qualquer acréscimo posterior.

$\mathrm{N}$ a verdade, o WACC nunca foi tão bom para lidar com os efeitos colaterais financei ros. Em suas formulações mais comuns, trata apenas dos aspectos tributários, e, mesmo

\section{Valor de todos os efeitos colaterais do financiamento}

benefícios fiscais da despesa financeira

custos de dificuldades financeiras

subsídios

hedges

Custos de emissão

outros custos 
assim, de maneira não muito convincente, a não ser no caso de estruturas de capital simples. Mas sua virtude está em exigir apenas uma operação de desconto, o que era uma bênção nos tempos das calculadoras e réguas de cál culo. Hoje, essa vantagem é irrelevante. As planilhas de alta velocidade fazem pouco da trabalheira que representam as operações de desconto exigidas pelo VPA. M ais de 20 anos após o VPA ter sido proposto, sua decomposição dos componentes do valor, que sempre foi altamente informativa, passa a ser também muito acessível.

O VPA éflexível. Um analista habilidoso pode configurar uma avaliação da maneira que faça mais sentido para as pessoas envolvidas na administração de cada uma das partes. A estrutura básica pode ser altamente refinada ou customizada de acordo com os gostos e as circunstâncias, mas um exemplo simples pode ilustrar a idéia central.

\section{UM ESTUDO DE CASO DE VPA}

Roy Henry, presidente da Ibex Industries, está de ol ho num alvo de aquisição: a Acme Filters, uma divisão da SL Corporation. A Acme é um negócio maduro que vem apresentando desempenho inferior ao de seu setor nos últimos seis anos. Depois que uma campanha interna para el evar o desempenho da empresa a deixou próxima das expectativas da alta administração, a SL Corporation decidiu vender a Acme. Trabal hando com gestores de divisão da I bex que conhecem as operações da Acme, mais alguns profissionais de fora, Henry percebeu as seguintes oportunidades específicas de criação de valor:

- A linha de produtos da Acme será racionalizada e alguns componentes serão terceirizados para melhorar a margem operacional da empresa em três pontos percentuais.

- As mesmas mudanças reduzirão os custos e aumentarão as contas a pagar, produzindo uma redução pontual do capital de giro líquido.

- Alguns dos ativos não produtivos da Acme serão vendidos.

- A distribuição será simplificada e serão introduzidos novos incentivos às vendas para aumentar 0 crescimento do faturamento da Acme de $2 \%$ a $3 \%$ ao ano para a média do setor, de $5 \%$.

- Haverá economia em alguns impostos, principal mente por meio de benefícios fiscais financeiros associados ao endividamento.
Os representantes dos vendedores indicaram que a SL Corporation reluta em aceitar menos do que o valor escritural (atual mente de \$307 milhões) pela Acme, apesar do mau desempenho recente. Os peritos financeiros de Henry acreditam que uma transação pelo valor escritural poderia ser financiada com cerca de $80 \%$ de endividamento, abrangendo endividamento bancário, dívida secundária de colocação privada e uma linha de crédito rotativa (ver Tabela 1). Henry espera liquidar essa dívida o mais rapidamente possível (e seus credores insistirão nisso) e chegar a uma proporção exigível/não exigível de $50 \%$ na estrutura do capital dentro de cinco anos. Ele irá tentar manter as comissões abaixo de 15 milhões, mas elas poderiam perfeitamente chegar a $\$ 20$ milhões ou até mais.

A Acme não tem ações negociadas em bolsa, mas algumas empresas parecidas têm e elas servem de benchmark para estimar o custo do patrimônio líquido. Uma empresa dessas, com taxa de endividamento histórica de $45 \%$ a $50 \%$, tem custo estimado do patrimônio líquido de $24 \%$. Outra, que não tem dívida em sua estrutura de capital, tem custo estimado do patrimônio líquido de $13,5 \%$. De modo geral, os investidores nas ações de Henry esperam rendimentos significativamente mais elevados - de $30 \%$ a 35\%. Para fins de comparação, digamos que o rendimento sobre títulos de longo prazo do governo seja de $5 \%$.

\section{REALIZAÇÃO DE UMA ANÁLISE DE VPA}

Vamos, agora, estimar o VPA desse alvo de aquisição. A primeira tarefa é avaliar a empresa como se fosse totalmente financiada por capital próprio, sem lançar mão de endividamento. Em seguida, como ela não será inteiramentefinanciada com capital próprio, acrescentaremos ou subtrairemos o valor associado ao programa de financiamento que pretendemos usar (ver Figura 2). Presumimos que o efeito líquido do programa seja positivo; do contrário, usaríamos apenas capital próprio.

Para determinar o valor da Acme Filters usando o VPA, seguimos os cinco passos apresentados na seqüência deste artigo.

\section{Primeiro passo: delinear os fluxos de caixa de base}

0 val or-base se constrói a partir das projeções financeiras que seriam preparadas para qual quer abordagem por FCD a esse problema, inclusive a valoração WACC que a maioria das empresas já usa. As projeções consistem nos fluxos de caixa operacionais e de investimentos incrementais esperados para a empresa-alvo. Confira os valores referentes 
à Acmena Tabela 1 (para poupar espaço, omitimos os itens acima da linha que entram na projeção de Ebit).

No primeiro ano, por exemplo, Henry espera um fluxo de caixa operacional, descontados os impostos, de \$36,5 milhões. A tabela mostra uma redução (entrada líquida) de capital de giro líquido no primeiro ano, com a liquidação do estoque e 0 aumento das contas a pagar, seguido de um novo investimento (uma saída líquida) para sustentar o crescimento subseqüente das vendas. As despesas de capital representam outra saída de caixa.
Final mente, a variação de outros ativos usa os recursos em caixa, descontados os impostos da liquidação dos ativos não produtivos mencionados anteriormente. 0 fluxo de caixa operacional, mais ou menos esses efeitos de investimento, nos dá o "fluxo de caixa livre dos ativos".

\section{Segundo passo: descontar os fluxos usando uma taxa de desconto e um valor terminal apropriados}

Como em qualquer valoração por FCD, precisamos de uma taxa de desconto e de um valor terminal. É no tra-

Figura 2 - Etapas de uma análise VPA básica.

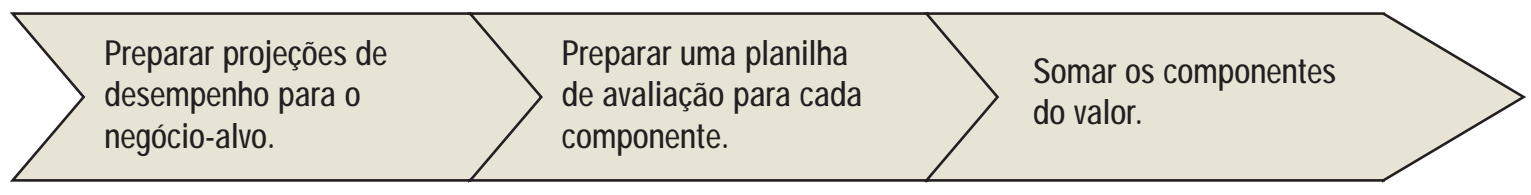

1o Passo:

Preparar projeções de desempenho e fluxos de caixa incrementais básicos do negócio

Empresa como um todo

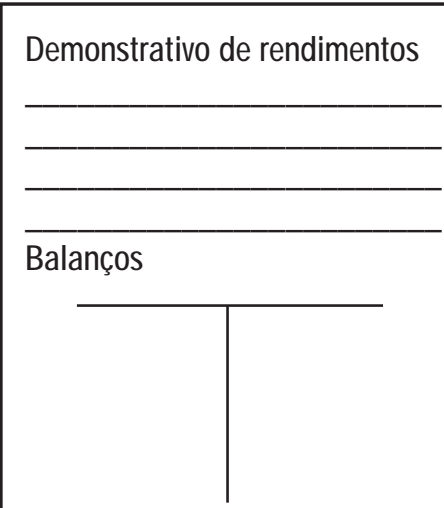

Fluxo de caixa básico

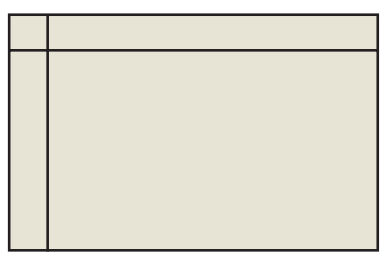

Aqui são agrupados os componentes de valor 2o Passo:

Descontar fluxos de caixa básicos e o valor terminal ao valor presente

Planilha de avaliação do caso-base

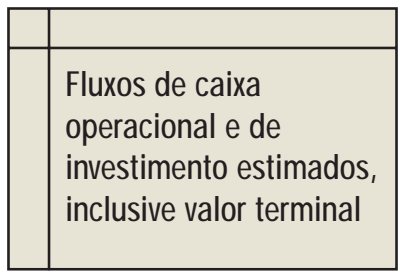

30 Passo:

Avaliar efeitos colaterais financeiros

Efeito colateral: benefício fiscal dos juros

Valor presente dos benefícios fiscais estimados do endividamento

Aqui são 'desagrupados' 4o Passo:

Somar os componentes e obter um VPA inicial

VPA

Valor básico

+ Valor dos efeitos colaterais financeiros

= Valor presente ajustado

50 Passo:

Adequar a análise às necessidades dos gestores 
Tabela 1 - Primeiro passo: preparar previsões de desempenho.

\begin{tabular}{|c|c|c|c|c|c|c|}
\hline \multicolumn{7}{|c|}{ DEMONSTRATIVOS DE RESULTADOS PRO-FORMA (EM MILHÕES DE DÓLARES) } \\
\hline & Ano 0 & Ano 1 & Ano 2 & Ano 3 & Ano 4 & Ano 5 \\
\hline EBIT & & $\$ 22,7$ & 29,8 & 37,1 & 40,1 & 42,1 \\
\hline Despesa financeira & & 21,6 & 19,1 & 17,8 & 16,7 & 15,8 \\
\hline EBT & & 1,1 & 10,7 & 19,3 & 23,3 & 26,3 \\
\hline Imposto a $34 \%$ & & 0,4 & 3,6 & 6,6 & 7,9 & 8,9 \\
\hline Resultado líquido & & 0,7 & 7,1 & 12,7 & 15,4 & 17,3 \\
\hline \multicolumn{7}{|l|}{ Dados complementares } \\
\hline Depreciação & & $\$ 21,5$ & 13,5 & 11,5 & 12,1 & 12,7 \\
\hline Despesas de capital & & 10,7 & 10,1 & 10,4 & 11,5 & 13,1 \\
\hline$\Delta$ capital operacional & & $-12,3$ & 1,9 & 4,2 & 5,2 & 6,1 \\
\hline$\Delta$ outros ativos & & 9,0 & 6,9 & 3,4 & 0,0 & 0,0 \\
\hline \multicolumn{7}{|c|}{ BALANÇOS PRO-FORMA (EM MILHÕES DE DÓLARES) } \\
\hline Ativo & Ano 0 & Ano 1 & Ano 2 & Ano 3 & Ano 4 & Ano 5 \\
\hline Capital de giro líquido & $\$ 60,0$ & 47,7 & 49,6 & 53,7 & 59,0 & 65,1 \\
\hline Ativo fixo líquido & 221,0 & 210,3 & 206,9 & 205,7 & 205,1 & 205,5 \\
\hline Outros ativos & 26,0 & 17,0 & 10,1 & 6,7 & 6,7 & 6,7 \\
\hline Total do ativo & 307,0 & 275,0 & 266,5 & 266,2 & 270,8 & 277,3 \\
\hline \multicolumn{7}{|l|}{ Passivo e capital social } \\
\hline Linha rotativa a 7,5\% & $\$ 13,0$ & 0,2 & 4,8 & 11,7 & 20,9 & 20,0 \\
\hline Empréstimo bancário a $8,0 \%$ & 80,0 & 60,0 & 40,0 & 20,0 & 0,0 & 0,0 \\
\hline Dívida subordinada a 9,5\% & 150,0 & 150,0 & 150,0 & 150,0 & 150,0 & 0,0 \\
\hline Debêntures de longo prazo a 9,0\% & 0,0 & 0,0 & 0,0 & 0,0 & 0,0 & 140,0 \\
\hline Total da dívida & 243,0 & 210,2 & 194,8 & 181,7 & 170,9 & 160,0 \\
\hline Capital social & 64,0 & 64,7 & 71,8 & 84,5 & 99,9 & 117,2 \\
\hline Total do passivo e do capital social & 307,0 & 275,0 & 266,5 & 266,2 & 270,8 & 277,3 \\
\hline \multicolumn{7}{|l|}{ Dados complementares } \\
\hline Juros & $\$ 0,0$ & 21,6 & 19,1 & 17,8 & 16,7 & 15,8 \\
\hline Principal & 0,0 & 32,8 & 15,5 & 13,1 & 10,8 & 10,9 \\
\hline Dividendos & 0,0 & 0,0 & 0,0 & 0,0 & 0,0 & 0,0 \\
\hline \multicolumn{7}{|c|}{ FLUXOS DE CAIXA DO CASO-BASE (EM MILHÕES DE DÓLARES) } \\
\hline & Ano 0 & Ano 1 & Ano 2 & Ano 3 & Ano 4 & Ano 5 \\
\hline EBIT & & $\$ 22,7$ & 29,8 & 37,1 & 40,1 & 42,1 \\
\hline - Impostos a $34 \%=$ & & 7,7 & 10,1 & 12,6 & 13,6 & 14,3 \\
\hline$=\mathrm{EBIT}(1-\mathrm{t})$ & & 15,0 & 19,6 & 24,5 & 26,4 & 27,8 \\
\hline + Depreciação & & 21,5 & 13,5 & 11,5 & 12,1 & 12,7 \\
\hline = Fluxo de caixa operacional & & 36,5 & 33,1 & 36,0 & 38,5 & 40,4 \\
\hline - $\Delta$ Capital de giro líquido & & 12,3 & $-1,9$ & $-4,2$ & $-5,2$ & $-6,1$ \\
\hline - Despesas de capital & & $-10,7$ & $-10,1$ & $-10,4$ & $-11,5$ & $-13,1$ \\
\hline - $\Delta$ Outros ativos & & 9,0 & 6,9 & 3,4 & 0,0 & 0,0 \\
\hline = Fluxo de caixa livre dos ativos & & 47,0 & 28,1 & 24,8 & 21,8 & 21,3 \\
\hline
\end{tabular}


tamento dado a esses itens que o VPA começa a se diferenciar dos outros métodos. Vamos começar pela taxa de desconto.

Queremos chegar a um custo de oportunidade do capital, ou seja, o retorno que os investidores de Henry podem esperar obter se investirem em outros ativos com 0 mesmo risco que os ativos-alvo representariam se financiados inteiramente com capital próprio. Nosso melhor benchmark para esse custo de oportunidade é 13,5\% - 0 custo do capital próprio (equity) de uma empresa comparável, cuja estrutura de capital inclui apenas o não exigível (equity).

O último ingredienteé um valor terminal para os ativos. Isso ésimplesmente uma estimativa, em al gum horizonte terminal, do valor dos ativos, levando em conta tudo 0 que ocorrer após o horizonte terminal. Para uma empresa em atividade normal mente escolhemos, como horizonte terminal, o primeiro momento a partir do qual os ativos podem ser vistos como perpétuos ou algum outro construto financeiro simples. Suponhamos que esperamos que o fluxo de caixa livre do ano seis em diante cresça $5 \%$ ao ano, perpetuamente. 0 valor (ao fim do ano cinco) de tal perpetuidade é simplesmente 0 fluxo de caixa do ano seis dividido pelo resultado da taxa de desconto, menos a taxa de crescimento $(0,135-0,05=0,085)$, o que corresponde a \$ 263,4 milhões.

Agora, descontamos os fluxos de caixa livres e o valor terminal a 13,5\%, como mostra a Tabela 2, para obter um valor-base de $\$ 244,5$ milhões. Observe que esse valor é inferior ao valor escritural que o vendedor gostaria de receber.

\section{Terceiro passo: avaliar os efeitos colaterais do financiamento}

Dentre os diversos efeitos colaterais possíveis do programa de financiamento proposto por Henry, examinaremos apenas um neste texto: os benefícios fiscais do endividamento. Tais benefícios surgem devido à dedutibilidade da despesa financeira nas demonstrações de resultados das empresas (contra a indedutibilidade dos dividendos). E por que seria isso um efeito colateral? Porque os pagamentos de impostos projetados no caso básico são elevados demais - a empresa hipotética financiada apenas com capital próprio não paga juros e não faz jus à dedução dos impostos. Com a estrutura de capital que Henry tem em vista, a dedução da despesa financeira reduzirá o resultado tributável no montante dos juros pagos e, com isso, reduzirá o imposto devido num montante equival ente à despesa financeira multiplicada pela alíquota. N o primeiro ano o benefício fiscal da despesa financeira é de $\$ 7,4$ milhões ( $\$ 21,6$ milhões $\times 0,34$ ). No segundo ano é de \$ 6,5 milhões, e assim por diante, como demonstrado.

Como no caso básico, ainda precisamos de um valor terminal e de uma taxa de desconto. Há consenso entre os acadêmicos no sentido de que os ben efícios fiscais, como qualquer outro fluxo de caixa futuro, deve ser descontado a uma taxa ajustada ao risco "apropriada", ou seja, uma taxa que reflita o nível de risco. Infelizmente, esses mesmos acadêmicos não chegam a um acordo sobre o quanto os benefícios fiscais são arriscados. Um expediente comum é usar o custo da dívida como taxa de desconto, partindo da teoria de que os benefícios são tão incertos quanto os pagamentos do principal e dos juros.

É claro que pode haver um momento em que seja possível fazer os pagamentos da dívida, mas não usar 0 benefício fiscal. Isso sugere que os benefícios fiscais são um pouco mais incertos e, portanto, merecedores de uma taxa de desconto um pouco mais alta. Outros argumentam em favor de uma taxa de desconto ainda mais elevada, observando que os administradores irão ajustar a alavancagem para mais ou para menos de acordo com a conjuntura dos negócios ou com o destino da empresa. N esse caso, a despesa financeira futura, juntamente com os benefícios fiscais, irá flutuar pelos mesmos motivos que os fluxos de caixa operacionais e, portanto, deverá receber a mesma taxa de desconto. Seguindo a abordagem mais comum, usamos uma taxa de desconto de $9,5 \%$ - um pouco mais do que o custo médio da dívida e, portanto,

Tabela 2 - Segundo passo: descontar os fluxos de caixa do caso-base e o valor terminal ao valor presente.

\begin{tabular}{|l|c|c|c|c|c|c|}
\hline & VALOR DO CASO-BASE (EM MILHÕES DE DÓLARES) & & \\
\hline & Ano 0 & Ano 1 & Ano 2 & Ano 3 & Ano 4 & Ano 5 \\
\hline Fluxo de caixa livre dos ativos & & $\$ 47,0$ & 28,1 & 24,8 & 21,8 & 21,3 \\
\hline Valor terminal dos ativos & & & & & & 263,4 \\
\hline Fator de desconto a 13,4\% & 1,0000 & 0,8811 & 0,7763 & 0,6839 & 0,6026 & 0,5309 \\
\hline Valor presente a cada ano & & $\$ 41,4$ & 21,8 & 17,0 & 13,1 & 151,1 \\
\hline Valor do caso-base (total) & $\mathbf{\$ 2 4 4 , 5}$ & & & & & \\
\hline
\end{tabular}


do lado mais alto do extremo inferior da faixa que acabamos de descrever.

Quanto ao val or terminal, suponhamos primeiramente que ao fim do ano cinco a empresa refinancie sua dívida com uma nova emissão de $\$ 140$ milhões em debêntures de longo prazo a $9 \%$. E que nos anos posteriores o endividamento cresça junto com a empresa. Digamos que cresça 5\%. E por fim, que os benefícios fiscais tenham 0 mesmo crescimento. No ano cinco, o valor desse fluxo perpetuamente crescente de benefícios fiscais será de \$122 milhões. Descontando todos os benefícios fiscais ao seu valor presente, chegamos a um valor de \$101,8 milhões para esse efeito colateral.

\section{Quarto passo: somar os componentes para obter um VPA inicial}

Somando o valor-base e o valor dos benefícios fiscais, obtemos uma estimativa inicial do VPA da empresa-alvo:

$$
\begin{aligned}
& \text { VPA }=\$ 244,5 \text { milhões (valor-base) }+\$ 101,8 \text { milhões } \\
& \text { (valor dos efeitos colaterais) }=\$ 346,3 \text { milhões. }
\end{aligned}
$$

Dizemos que se trata de uma estimativa inicial por dois motivos. Primeiro, desconsideramos outros efeitos colaterais do financiamento para abreviar a apresentação. E segundo, mesmo neste exemplo simplificado, podemos levar a análise do VPA adiante para obter mais esclarecimentos. A té este ponto, nossa anál ise sugere que comprar esta empresa por \$ 307 é um bom negócio: Henry irá au- mentar a riqueza de seus investidores na medida do valor presente líquido da aquisição, ou cerca de \$ 29 milhões (VPL $=\$ 343,6$ milhões $-\$ 307$ milhões).

\section{Quinto passo: ajustar a análise às necessidades dos administradores}

Que parte do val or da Acme já existe e quanto será criado por Henry ao assumir a propriedade e implementar mudanças? Q uanto valor cada uma das iniciativas planejadas agrega? Os executivos responsáveis pela realização desse val or sabem de quanto se trata? Sabem do que depende? Finalmente, quanto do valor a ser criado será pago ao vendedor no fechamento? 0 quinto passo de uma análise VPA pode examinar todas essas questões administrativas pertinentes e outras mais.

Comecemos decompondo as projeções de fluxo de caixa do caso básico em fluxos de caixa associados às iniciativas de criação de valor de Henry. Na Tabela 5, os fluxos de caixa do caso básico encontram-se decompostos. Os fluxos de caixa-base são derivados de resultados operacionais recentes e representam o negócio em sua atual configuração de baixo desempenho. Há, então, incrementos para cada uma das iniciativas propostas: ganhos de margem; melhorias de capital de giro líquido; liquidação de ativos; e maior crescimento estável. Quando tributamos e descontamos cada um desses, vemos que o valor-base do negócio é de \$ 157 milhões e que os ganhos operacionais acrescentariam \$ 87 milhões (esses dois valores excluem benefícios fiscais).

Tabela 3 - Terceiro passo: avaliar os efeitos colaterais do financiamento.

\begin{tabular}{|l|c|c|c|c|c|c|c|}
\hline \multicolumn{1}{|c|}{ BENEFÍCIOS FISCAIS DA DESPESA FINANCEIRA (EM MILHÕES DE DÓLARES) } \\
\hline & Ano 0 & Ano 1 & Ano 2 & Ano 3 & Ano 4 & Ano 5 \\
\hline Benefício fiscal da despesa financeira & & $\$ 7,4$ & 6,5 & 6,1 & 5,6 & 5,4 \\
\hline Valor terminal dos benefícios fiscais & & & & & & 122,4 \\
\hline Fator de desconto a 9,5\% & 1,000 & 0,9132 & 0,8340 & 0,7617 & 0,6956 & 0,6352 \\
\hline Valor presente a cada ano & & $\$ 6,7$ & 5,4 & 4,6 & 3,9 & 81,2 \\
\hline Valor presente total dos benefícios fiscais & $\mathbf{\$ 1 0 1 , 8}$ & & & & & \\
\hline
\end{tabular}

Tabela 4 - Quarto passo: somar os componentes para obter um VPA inicial.

\begin{tabular}{|l|c|c|c|c|c|c|}
\hline \multicolumn{5}{|c|}{ VALOR PRESENTE AJUSTADO (EM MILHÕES DE DÓLARES) } \\
\hline & Ano 0 & Ano 1 & Ano 2 & Ano 3 & Ano 4 & Ano 5 \\
\hline Valor do caso-base & $\$ 244.5$ & & & & \\
\hline Efeitos colaterais: benefícios fiscais & $\$ 101,8$ & & & & \\
\hline Valor presente ajustado & $\$ \mathbf{3 4 6 , 3}$ & & & & \\
\hline
\end{tabular}


Cerca de um terço dos $\$ 87$ milhões vem de iniciativas de curto prazo: venda de ativos improdutivos e redução do capital de giro. 0 restante vem de iniciativas sustentadas: mel horia das margens e expansão do crescimento. 0 mais provável é que essas quatro tarefas sejam confiadas a pessoas diferentes. É crucial que elas cumpram bem suas funções, uma vez que, embora sejam criados \$ 87 milhões, apenas \$ 39 milhões destes (o VPL) ficarão nas mãos dos novos proprietários. 0 restante irá para o vendedor como parte do preço de venda.

Tabela 5 - Quinto passo: ajustar a análise às necessidades dos administradores.

\begin{tabular}{|c|c|c|c|c|c|c|}
\hline \multicolumn{7}{|c|}{ DESEMPENHO PELO CASO-BASE (EM MILHÕES DE DÓLARES) } \\
\hline & Ano 0 & Ano 1 & Ano 2 & Ano 3 & Ano 4 & Ano 5 \\
\hline Base do EBIT & & $\$ 20,4$ & 26,8 & 33,4 & 36,1 & 37,9 \\
\hline - Impostos@34\% & & 7,0 & 9,1 & 11,4 & 12,3 & 12,9 \\
\hline$=\mathrm{EBIT}(1-\mathrm{t})$ & & 13,5 & 17,7 & 22,0 & 23,8 & 25,0 \\
\hline + Depreciação & & 21,5 & 13,5 & 11,5 & 12,1 & 12,7 \\
\hline = Fluxo de caixa operacional & & 35,0 & 31,1 & 33,5 & 35,9 & 37,7 \\
\hline - $\Delta$ Capital de giro & & $-4,0$ & $-4,0$ & $-4,2$ & $-5,2$ & $-6,1$ \\
\hline - Despesas de capital & & $-10,7$ & $-10,1$ & $-10,4$ & $-11,5$ & $-13,1$ \\
\hline = Base do fluxo de caixa livre & & 20,2 & 17,0 & 19,0 & 19,2 & 18,5 \\
\hline Base valor terminal & & & & & & 172,8 \\
\hline Fator de desconto @ 13,5\% & 1,0000 & 0,8811 & 0,7763 & 0,6839 & 0,6026 & 0,5309 \\
\hline Valor presente a cada ano & & $\$ 17,8$ & 13,2 & 13,0 & 11,5 & 101,6 \\
\hline Base do valor do negócio & $\$ 157,2$ & & & & & \\
\hline \multicolumn{7}{|c|}{ INCREMENTOS: INICIATIVAS DE CRIAÇÃO DE VALOR (EM MILHŌES DE DÓLARES) } \\
\hline & Ano 0 & Ano 1 & Ano 2 & Ano 3 & Ano 4 & Ano 5 \\
\hline \multicolumn{7}{|l|}{ 1. Ganhos de margem } \\
\hline EBIT Incremental & & $\$ 2,3$ & 3,0 & 3,7 & 4,0 & 4,2 \\
\hline - Impostos @ 34\% & & 0,8 & 1,0 & 1,3 & 1,4 & 1,4 \\
\hline - Incremento de caixa & & 1,5 & 2,0 & 2,4 & 2,6 & 2,8 \\
\hline Incremento do valor terminal & & & & & & 25,9 \\
\hline Valor presente a cada ano (@13,5\%) & & 1,3 & 1,5 & 1,7 & 1,6 & 15,2 \\
\hline Valor do ganho de margem & $\$ 21,3$ & & & & & \\
\hline \multicolumn{7}{|l|}{ 2. Ganho de capital de giro líquido } \\
\hline Fluxo de caixa incremental & & $\$ 16,3$ & 2,1 & & & \\
\hline Valor presente a cada ano (@13,5\%) & & 14,4 & 1,7 & & & \\
\hline Valor do ganho de capital de giro líquido & $\$ 16,0$ & & & & & \\
\hline \multicolumn{7}{|l|}{ 3. Vendas de ativos } \\
\hline Fluxo de caixa incremental & & $\$ 9,0$ & 6,9 & 3,4 & & \\
\hline Valor presente a cada ano (@ 13,5\%) & & 7,9 & 5,4 & 2,3 & & \\
\hline Valor da venda de ativos & $\$ 15,6$ & & & & & \\
\hline \multicolumn{7}{|l|}{ 4. Maior crescimento estável } \\
\hline Valor terminal incremental & & & & & & $\$ 64,7$ \\
\hline Valor do maior crescimento & $\$ 34,3$ & & & & & \\
\hline Soma da base e dos incrementos & $\$ 244,5$ & & & & & \\
\hline + Valor dos benefícios fiscais da dívida & $\$ 101,8$ & (como ante & & & & \\
\hline Valor presente ajustado & $\$ 346,3$ & (como ante & & & & \\
\hline
\end{tabular}


Poderíamos estender a análise de diversas maneiras, dependendo daquilo que seria de utilidade para os administradores, negociadores ou financiadores. Poderíamos examinar diferentes cenários para cada categoria. Poderíamos reavaliar os benefícios fiscais para tratar das diferentes estruturas propostas para o negócio ou alocar capacidade de endividamento às diferentes partes do negócio ou a diferentes iniciativas específicas. Poderíamos reavaliar o risco, possivelmente ajustando as taxas de desconto das valorações dos elementos componentes.

Suponhamos, por exemplo, que os ganhos de capital de giro venham, predominantemente, da liquidação de estoques excessivos de matérias-primas: 0 fluxo de caixa associado provavelmente conteria menos risco de negócio do que os fluxos de caixa operacionais normais e, portanto, mereceriam taxa de desconto inferior a 13,5\%. Alternativamente, suponhamos que os ganhos de margem viessem de uma maior automação e, portanto, de custos

Figura 3 - 0 VPA é rico em informações (em milhões de dólares). fixos mais elevados: isso sugeriria que esses fluxos de caixa incrementais mereciam uma taxa de desconto algo mais el evada.

Essas análises poderiam ser realizadas com o WACC? Possivelmente, mas primeiro teríamos que calcular corretamente o WACC (ver Quadro 1). Então, se quiséssemos considerar que diferentes fluxos de caixa podem ter diferentes características de risco e, portanto, merecer diferentes taxas de desconto, calcularíamos o WACC de todas as diferentes iniciativas criadoras de valor. Isso nos forçaria a pensar sobre a estrutura de capital, por exemplo, nos ganhos de capital de giro. E a taxa de endividamento dessa estrutura foi expressa em val ores de mercado ou escriturais? A taxa muda com o tempo? 0 exercício é ainda mais sujeito a erros do que a mera formulação que consta do quadro. 0 VPA é, ao mesmo tempo, menos trabal hoso e mais informativo.

A "marca registrada" do VPA é que taxa de desconto
VPA: \$ 346

Maior crescimento: \$ 34

Vendas de ativos: $\$ 16$

Ganho de fluxo de caixa líquido: \$ 16

Ganho de margem: \$ 21

Benefício fiscal da despesa financeira: \$ 102

Valor-base do negócio: \$ 157

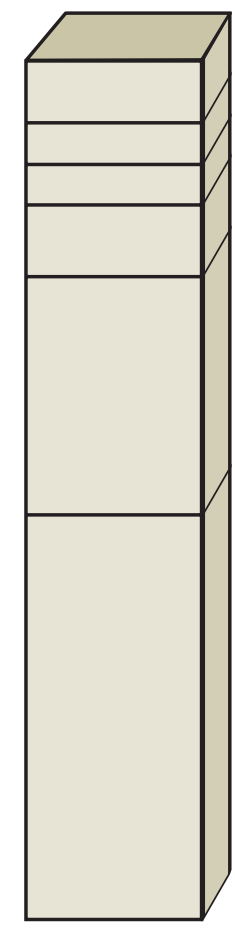

Fontes de valor
VPA: $\$ 346$

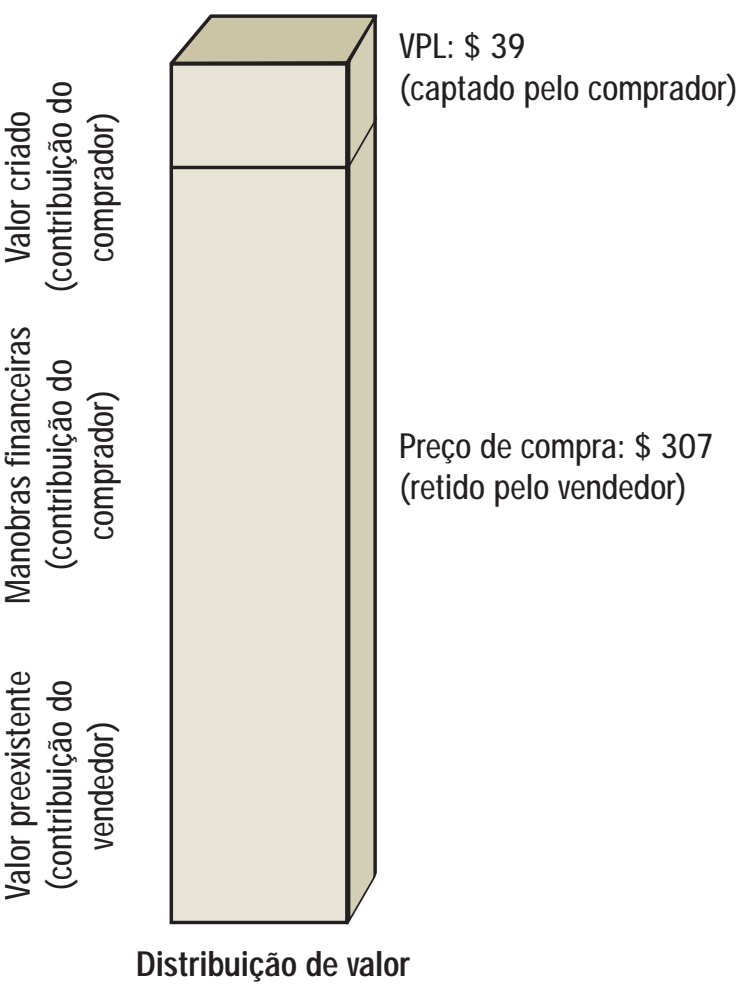

Observação: Embora o comprador esteja criando \$ 87 milhões - e ainda mais e economias de impostos -, tudo é pago ao vendedor, exceto \$39 milhões. 
al guma contém qualquer coisa al ém do valor no tempo (a taxa de juros livre de risco) e um prêmio pelo risco (segundo o risco dos fluxos de caixa que estão sendo descontados). Qualquer valor criado por manobras financeiras - economia de impostos, gestão de risco, dívida subsidiada, dívida aprimorada por crédito - tem suas próprias conseqüências para o fluxo de caixa. Lidamos com essas conseqüências distribuindo os fluxos de caixa numa planilha e descontando-os a uma taxa que reflita o valor no tempo e seu risco, mas nada mais do que isso. Em ouras palavras, o VPA é excepcionalmente transparente: podemos ver todos os componentes de valor da análise; nenhum deles está oculto em ajustes à taxa de desconto.

0 VPA tem suas limitações, é claro. Algumas são questões de purismo, al go que interessa mais aos acadêmicos do que aos administradores. Mas duas, em especial, são importantes de se conhecer porque introduzem vieses consistentes na análise. Primeiro, a renda advinda de ações, ao contrário da devida a bônus, pode ser taxada de maneira diferente se 0 investidor apresentar declaração de imposto da pessoa física. Isso normalmente faz com que 0 anal ista superestime a vantagem líquida associada aos empréstimos corporativos ao calcular o valor presente dos benefícios fiscais da despesa financeira. Segundo, a maioria dos analistas negligencia os custos de dificuldades financeiras associados à alavancagem corporativa e podem ignorar, também, outros efeitos colaterais finan-

Quadro 1 - As armadilhas no uso de WACC.

Podemos avaliar a Acme Filters sem VPA, usando as mesmas projeções de fluxo de caixa pró-forma e descontando ao custo médio ponderado do capital (WACC). Infelizmente, esse procedimento não é tão simples quanto os manuais fazem parecer. Um esboço da abordagem de muitas empresas que adotam essa análise destaca algumas de suas armadilhas.

Numa análise baseada em WACC, o desconto se dá apenas uma vez - a taxa de desconto precisa ser ajustada para captar todos os custos e benefícios de uma estrutura de capital selecionada. Não surpreende que 0 cálculo dessa taxa exija grande esforço analítico. O WACC é exatamente aquilo que diz ser: uma média ponderada dos custos, descontados os impostos das diferentes fontes de capital, cada uma ponderada pela fração da estrutura de capital que representa. Em nosso exemplo, há três tipos de dívida (quatro, se considerarmos 0 refinanciamento do ano cinco) e um tipo de patrimônio líquido. Veja os cálculos apresentados na tabela para observar como chegamos a um WACC de $9,7 \%$. ceiros de interesse. Em termos mais gerais, devemos ter em mente que, com toda a sua versatilidade, o VPA ainda é uma metodologia de $F C D$, sendo pouco adequado à avaliação de projetos que sejam, essencialmente, opções. As formulações mais comuns do WACC sofrem das mesmas limitações e ainda outras.

O que fazer para aprender a usar o VPA? A boa notícia é que, se você chegou até aqui, provavelmente já aprendeu: o conceito básico é, de fato, simples mesmo. Claro que há formulações mais sofisticadas que examinam, por exemplo, outros efeitos colaterais, como garantias financeiras ou subsídios. Ademais, deixei de mencionar al guns conceitos interessantes que ajudam a selecionar ou criar taxas de desconto sensatas, por exemplo, e reconciliar diferentes benchmarks do custo do patrimônio líquido. Os conceitos relevantes estão bem descritos em textos básicos de finanças corporativas. Para um panorama das formulações mais sofisticadas, procure livros dedicados a problemas financei ros; 0 exemplo clássico éo da avaliação horizontal (cross border valuation) para a qual o VPA é de enorme utilidade. Fora isso, você só precisa de prática.

Artigo originalmente publicado por Timothy A. Luehrman, sob 0 título "Using APV: A better tool for Valuing O perations", na Harvard Business Review, maio-junho, p.145-154, 1997. Reproduzido em língua portuguesa com autorização de @ N ew York Times Sindicate. www.nytsyn.com
Quando descontamos os fluxos de caixa livres dessa empresa a 9,7\%, obtemos um valor do negócio de $\$ 417$ milhões, 0 que implica um VPL de aproximadamente $\$ 110$ milhões (VPL = $\$ 417$ milhões - \$ 307 milhões). Isso equivale a $275 \%$ do valor que obtivemos pelo VPA, que já era provavelmente uma superestimativa. Evidentemente, se Henry entrasse num leilão pela empresa e a arrematasse por $\$ 417$ milhões, transferiria muito valor de seus investidores para os acionistas do vendedor.

Por que tamanha diferença entre os valores das estimativas? Os motivos são vários, mas o mais importante é que cometemos alguns erros comuns e calculamos incorretamente o WACC. Vamos partir do custo do patrimônio líquido, que admitimos ser de $24 \%$. Um de nossos benchmarks do custo do patrimônio foi outra empresa do mesmo setor que tinha cerca de $50 \%$ de dívida em sua estrutura de capital. 0 custo do patrimônio dessa empresa era de $24 \%$. Como estamos visando o mesmo nível de alavancagem, 24\% parece ser uma estimativa razoável. Mas não chegaremos a essa estrutura 
Quadro 1 - continuação...

de capital até 0 ano cinco, e nesse meio tempo nossa alavancagem será substancialmente maior. Na verdade, nossa taxa de endividamento, no fechamento do negócio, será de aproximadamente $80 \%, 0$ que sugere custo do patrimônio de $40 \%$, não $24 \%$. Mas mesmo esse valor não pode ser usado isoladamente, já que o custo do patrimônio muda sempre que a taxa de endividamento se altera - a cada ano. Pelo mesmo motivo, simplesmente inserir $30 \%$ ou $35 \%$, o benchmark associado aos investidores de Henry, também seria enganoso. Em suma, nenhum dos toscos benchmarks que Henry tem à sua disposição é adequado ao WACC.

Outro problema é que usamos valores escriturais para gerar as ponderações do WACC, enquanto o procedimento só é válido com valores de mercado. Para exemplificar, admitamos que o valor do negócio no fechamento seja, efetivamente, de \$ 417 milhões. Isso implica uma taxa de endividamento ao valor de mercado de $58 \%$, não $80 \%$ ou $50 \%$. E também isso está sujeito a mudanças a cada ano. É claro que, se soubéssemos 0 real valor de mercado dos ativos, não precisaríamos fazer a análise. Um caminho é estimar o valor de mercado ou usar valores escriturais e então iterar - usar o valor de mercado calculado como nova estimativa e recomputar outra estimativa, e assim por diante, até que os valores estimados e computados convirjam.

E há ainda outras dificuldades. Na verdade, cada elemento do WACC apresenta desafios de cálculo em qualquer ambiente que não os mais simples e estéreis. Esses problemas podem ser solucionados? Na maioria dos casos, sim, embora a demonstração do mecanismo fuja ao objetivo deste artigo. Basta dizer que fazer os ajustes recomendáveis aos cálculos simplistas (mas muito comuns) aqui apresentados é tão difícil quanto usar o VPA - e menos informativo.

\begin{tabular}{|c|c|c|c|c|c|c|}
\hline \multicolumn{7}{|c|}{ CÁLCULOS DO WACC (EM MILHÕES DE DÓLARES) } \\
\hline Fonte de recursos & Montante & $\begin{array}{l}\text { Porcentagem } \\
\text { dos recursos }\end{array}$ & $\begin{array}{l}\text { Custo após } \\
\text { impostos }\end{array}$ & $\begin{array}{c}\text { Custo } \\
\text { ponderado }\end{array}$ & & \\
\hline \multicolumn{7}{|l|}{ Dívida: } \\
\hline Crédito rotativo \$ 7,5\% & $\$ 13$ & $4,2 \%$ & 0,050 & $0,2 \%$ & & \\
\hline Dívida bancária a 8,0\% & 80 & $26,1 \%$ & 0,053 & $1,4 \%$ & & \\
\hline Dívida subordinada a 9,5\% & 150 & $48,9 \%$ & 0,063 & $3,1 \%$ & & \\
\hline Patrimônio líquido & 64 & $20,8 \%$ & 0,240 & $5,0 \%$ & & \\
\hline Total dos recursos & 307 & $100,0 \%$ & & \multicolumn{3}{|c|}{$9,7 \%=$ WACC } \\
\hline \multicolumn{7}{|c|}{ DESCONTO DO FLUXO DE CAIXA LIVRE AO WACC } \\
\hline & Ano 0 & Ano 1 & Ano 2 & Ano 3 & Ano 4 & Ano 5 \\
\hline Fluxo de caixa livre dos ativos & & $\$ 47,0$ & 28,1 & 24,8 & 21,8 & 21,3 \\
\hline Valor terminal dos ativos & & & & & & 481,2 \\
\hline Fator de desconto (WACC) & & 0,9120 & 0,8317 & 0,7585 & 0,6917 & 0,6308 \\
\hline Valor presente a cada ano & & $\$ 42,9$ & 23,3 & 18,8 & 15,1 & 317,0 \\
\hline Valor do ativo (total) & $\$ 417,1$ & & & & & \\
\hline
\end{tabular}

\section{Artigo Convidado. Aprovado em 02.04.2007.}

\section{Timothy A. Luehrman}

Professor de Finanças da Harvard Business School.

Interesses de pesquisa nas áreas de avaliação de capitais, finanças corporativas, custo de capital, opções

reais e val oração.

E-mail: tluehrman@hbs.edu

Endereço: Harvard Business School. Finance Unit. Soldiers Field, Boston, MA - USA, 02163-9986. 